\title{
Erastin Analogue PRLX 93936
}

National Cancer Institute

\section{Source}

National Cancer Institute. Erastin Analogue PRLX 93936. NCI Thesaurus. Code C70625.

A structural analogue of erastin with potential antineoplastic activity. Erastin analogue PRLX 93936 appears to inhibit mitochondrial outer membrane protein VDACs (voltagedependent anion channels) 2 and 3, resulting in an oxidative, non-apoptotic cell death. Erastin analogue PRLX 93936 exhibits greater lethality in cell lines harboring mutations in the GT Pase protein oncogenes HRAS and KRAS or the serine-threonine protein kinase oncogene BRAF than in non-tumorigenic cell lines. VDACs 2 and 3 are up-regulated in a wide variety of tumor cell lines. 